\section{Recurrent Pregnancy Loss: Proposal for a Novel Diagnostic Protocol with New Molecular Genetics Insight}

\begin{abstract}
Carmelo Piscopo ${ }^{1 *}$, Gabriele Saccone ${ }^{2}$, Claudio Santangelo ${ }^{3}$, Achille Iolascon ${ }^{4,5}$ and Matteo Della Monica ${ }^{1}$
\end{abstract}

${ }^{1}$ Medical and Laboratory Genetics Unit, A Cardarelli Hospital, Naples, Italy

${ }^{2}$ Department of Neuroscience, Reproductive Sciences and Dentistry, School of Medicine, University of Naples Federico II, Naples, Italy

${ }^{3}$ Gynecology and Obstetrics unit, A Cardarelli Hospital, Naples, Italy

${ }^{4}$ Department of Molecular Medicine and Medical Biotechnology, University Federico II, Naples, Italy

${ }^{5}$ CEINGE Biotecnologie Avanzate, Naples, Italy

\section{Introduction}

Recurrent Pregnancy Loss (RPL) is defined as three consecutive Pregnancy Loss (PL) prior to 20 weeks of gestation, about $1-2 \%$ of women will be affected [1,2]. Recently, the American Society of Reproductive Medicine (ASRM) has redefined RPL as two or more pregnancy losses [3]. Using this definition, the incidence of RPL is up to $5 \%$ of women [1-3]. Different risk factors are associated with RPL, including advanced maternal age, and number of previous miscarriages [1]. Although RPL remains unexplained in about $50 \%$ of the cases, gynecological, endocrinological, immuno-hematological and genetical factors have been described.

\section{Gynecologic Factors}

The most common gynecologic factors associated with RPL are: (I) uterine malformations, (II) uterine fibroids, (III) uterine synechiae, (IV) infections and (V) progesterone deficiency.

I. Uterine malformations (i.e., Mullerian anomalies), such as septate uterus, can be up to three times more frequent in women with

*Corresponding author: Carmelo Piscopo, Medical and Laboratory Genetics Unit, A.Cardarelli Hospital, Naples, Italy, Tel: 39 0817472291; E-mail: carmelo.piscopo@ aocardarelli.it

Citation: Piscopo C, Saccone G, Santangelo C, Iolascon A, Monica MD (2020) Recurrent Pregnancy Loss: Proposal for a Novel Diagnostic Protocol with New Molecular Genetics Insight. J Genet Genomic Sci 4: 018.

Received: May 19, 2020; Accepted: May 21, 2020; Published: May 28, 2020

Copyright: (C) 2020 Piscopo C, et al. This is an open-access article distributed under the terms of the Creative Commons Attribution License, which permits unrestricted use, distribution, and reproduction in any medium, provided the original author and source are credited. history of RPL $[2,3]$. However, surgical treatment of malformations does not seem to be associated with an improved reproductive outcome [4].

II. The intramural and submucosal fibroids could increase the risk of miscarriage and decrease live birth rate. However, there are still limited evidence on benefits of surgical treatment of uterine fibroids on reproductive outcomes [5].

III. There is some evidence that the uterine synechiae (Asherman's syndrome) may cause infertility and the RPL [6].

IV. Given the factors described above, it may be reasonable to look for uterine factors in young women with RPL, including ultrasound scan also with the three-dimensional approach or with sonohysterography, according to the local resource.

V. Regarding the potential role of local infections, the role of Ureaplasma, Chlamydia and Mycoplasma, or other agents, is still a subject of debate. Therefore, detection and therapy for these infections are not routinely recommended [2,3].

VI.The role of progesterone in RPL is controversial. Evidence showed that progesterone supports the pregnancy. For example, leutectomy prior to 7 weeks causes miscarriage, low progesterone levels have been linked to increase risk of first trimester miscarriage, and progesterone antagonist (mifepristone) have been successfully used in induction of abortion. Therefore, the central role of progesterone in early pregnancy led clinicians and researchers to hypothesize that progesterone deficiency could be a cause of some miscarriages. This hypothesis has results in numerous clinical trials of progesterone supplementation in early pregnancy bleeding, as well as in women with history of recurrent miscarriage. However, when studied in well designed placebo-controlled randomized trials, supplementation with progesterone did not result in improved reproductive outcome in women with RPL [7].

\section{Endocrinological Causes}

Endocrinological factors involved in RPL include (I) thyroid function, (II) glucose metabolism, (III) Polycystic Ovary Syndrome (PCOS) and (IV) hyperprolactinemia.

I. Because some data suggests that clinical or subclinical hypothyroidism is associated with RPL [3], many guidelines recommended testing for Thyroid-Stimulating Hormone (TSH) levels in RPL patients and treating only those with overt hypothyroidism [8].Our proposal is to test thyroids hormone levels in RPL patients and refer to endocrinologist in case of abnormal results.

II. Regarding glucose metabolism, different guidelines report that well controlled diabetes is not a risk factor for RPL [1] so we suggest testing glucose and glycosylated hemoglobin only in case of presence of clinical suspect.

III. A lot of studies were performed on the possible influence of PCOS on the pregnancy and RPL $[1,9]$ : however strong evidence of this 
hypothesis is still not present so routine screening for PCOS is not recommended for treatment or investigation of RPL $[1,10]$.

IV. Elevated prolactin may cause ovulatory dysfunction and infertility but its role in RPL is still controversial and unclear. The European Society of Human Reproduction and Embryology guidelines do not recommend testing prolactin in the absence of clinical suspicion, while the American Society for Reproductive Medicine states that testing can be considered [1]. There is some weak evidence to suggest that normalising hyperprolactinemia can improve live births in RPL [1]. Our suggestion is to test prolactin level only in case of signs or symptoms and eventually refer to a specialist.

\section{Immuno-Hematologic Causes}

Two main immuno-hematological issues are been involved in RPL: (I) a thrombophilic status with particular attention to antiphospholipid syndrome and (II) an autoimmune disregulation.

I. Thrombotic events can cause abortion at any time of pregnancy. A thrombophilic status can be due to specific genetic polimorphisms (see Genetical causes) or to other acquired conditions that can alter coagulation status of the patient. The most frequent of these acquired conditions in RPL patients is the presence of anticardiolipin and/or lupus anticoagulant antibodies that, when associated with pregnancy loss or thrombotic events, is also known as Antiphospholipid Syndrome (APS). The APS, by the direct inhibition of placenta ion or the disruption of adhesion molecules or the thrombosis of placental vasculature, can play an important role in the RPL pathogenesis [1]. There are a lot of studies that have demonstrated the correlation between RPL and APS [11]. In fact, many guidelines recommend testing the APS in RPL woman and also suggest treating RPL patients with APS positivity with aspirin and low molecular weight heparin [1-3]. Consequently our suggestion is to check complete coagulation profile and APS antibodies in RPL patients and to refer to hemostasis specialist if there are abnormal values.

II. There are a lot of studies that have investigated the potential role of immune system in the pathogenesis of RPL. This includes the study of human leukocyte antigen (HLA) typing, natural killer cells, proinflammatory interleukin polymorphisms and immunomodulation with, for example, intravenous immunoglobulin, corticosteroids, intralipid infusion, auto-transfusion of lymphocytes and platelet rich plasma [12-16]. Anyway there is limited evidence that immunodisregulation and/or immunomodulation has any effect on RPL so investigations for auto-immunity, outside of APS, are not recommended [1]. Thus we don't suggest any specific autoimmunity analyses, rather than those for APS.

\section{Genetical Causes}

To date, there are two principal genetics factors that can influence the pregnancy outcome: (I) the presence of chromosomal abnormalitiesand (II) the presence of genomic DNA mutations.

I. It has been calculated that about $50-60 \%$ of abortions is due to a lethal chromosomal abnormalities: complete trisomies, monosomies o polyploidies [17-21]. These aneuploidies are sporadic and generally originate from a non-disjunction maternal event [1921]. The diagnosis requests karyotype on the abortion specimens or, sometimes, Non Invasive Prentatal Test (NIPT) may be used.
Although these anomalies are frequent in spontaneous abortions, they are also isolated and couples experiencing this event do not present a significant risk of recurrence for future pregnancies. Unfortunately, in the majority of cases is not possible to perform the genetic tests on abortion specimens and the miscarriage remains idiopathic. An important part of these idiopathic abortions are due to a rearrangement of a chromosomal balanced anomaly present in one of the partners (translocation, inversion or insertion). It has been shown that in about $5 \%$ of couples with RPL, one of the partners carries a balanced asymptomatic chromosomal anomaly $[1,2]$ that can be transmitted in unbalanced lethal form to the offsprings. Moreover, this chromosomal rearrangement presents a relatively high risk of recurrence. Options for these couples include Pre-implantation Genetic Diagnosis (PGD), spontaneous conception with invasive testing of subsequent pregnancies to konw and avoid imbalance tramission (chorionic villus sampling or amniocentesis), gamete donation [1]. The preimplantation genetic diagnosis, using medically assisted procreation techniques, can exclude the possibility of transmitting unbalanced chromosomal anomalies by the genetic selection of embryos to transfer. Our suggestion is to perform peripherical standard karyotype for RPL couples that haven't diagnosis of miscarriage with completed aneuploidy. Our proposal is also to perform a high-resolution karyotyping, known as Comparative Genomic Hybridization Array, if they have normal standard karyotype but positive family history of RPL for the female partner. This new molecular technique can identify the woman with a rearrangement on $\mathrm{X}$ chromosome that could be lethal or pathogenetic for male's offspring.

II. If the RPL patients present positive familial history of a specific mendelian disease, the causative genes could be screened in partners in order to identify the pathogenetic mutations and eventually use the preimplantation genetic diagnosis. This therapeutical option can be applied also to consanguineous partners with RPL if the molecular analyses identify the specific mutations that cause the recurrent abortions. A lot of genes were studied and potentially involved in the pathogenesis of RPL such DYNC2H1, KIF14, RYR1, GLE1, AMN, THBD, PROCR, VEGF, TP53, NOS3, JAK2 and so many others $[22,23]$ but there is not a strong evidence of pathogenicity in miscarriage or recurrent gene mutations to test. So, except for rare cases, our opinion is that there isn't to date any specific gene or mutation related to RPL in general population that can be studied or proposed. However, many polymorphisms are under investigation, but the evidence is still limited. Between these, the polymorphisms related to thrombotic predisposition are been largely studied and often suggested [24-26]. A lot of papers have reported the association between V Leiden and Prothrombin polymorphisms and RPL [27-31]. Our proposal is to check complete coagulation biochemical screening with addition only of V Leiden and Prothrombin polymorphisms for all RPL patients. Finally, because it is now possible to investigate a lot of genes simultaneously using the next generation sequencing, we also suggest for all RPL woman that present a suggestive family history of male abortions to refer to geneticcounsellor in order to screen $\mathrm{X}$ linked gene diseases that are lethal in male. 
Citation: Piscopo C, Saccone G, Santangelo C, Iolascon A, Monica MD (2020) Recurrent Pregnancy Loss: Proposal for a Novel Diagnostic Protocol with New Molecular Genetics Insight. J Genet Genomic Sci 4: 018.

\section{References}

1. Hong Li Y, Marren A (2018) Recurrent pregnancy loss: A summary of international evidence-based guidelines and practice. Aust J Gen Pract 47: $432-436$

2. Royal College of Obstetricians and Gynaecologists (2011) The Investigation and Treatment of Couples with Recurrent First Trimester and Second Trimester Miscarriage. Royal College of Obstetricians and Gynaecologists, London, UK.

3. Practice Committee of the American Society for Reproductive Medicine (2012) Evaluation and treatment of recurrent pregnancy loss: A committee opinion. Fertil Steril 98: 1103-1111.

4. Rikken JFW, Verhorstert KWJ, Emanuel MH, Bongers MY, Spinder T, et al. (2020) Septum resection in women with a septate uterus: a cohort study. Hum Reprod.

5. Singh SS, Marsh EE (2017) Focus on uterine fibroids: evolving options to optimize care. Am J Obstet Gynecol 217: 626.

6. Hooker AB, Lemmers M, Thurkow AL, Heymans MW, Opmeer BC, et al. (2014) Systematic review and meta-analysis of intrauterine adhesions after miscarriage: Prevalence, risk factors and long-term reproductive outcome. Hum Reprod Update 20: 262-278.

7. Coomarasamy A, Williams H, Truchanowicz E, Seed PT, Small R, et al. (2015) A Randomized Trial of Progesterone in Women with Recurrent Miscarriages. N Engl J Med 373: 2141-2148.

8. Alexander EK, Pearce EN, Brent GA, Brown RS, Chen H, et al. (2017) Guidelines of the American Thyroid Association for the Diagnosis and Management of Thyroid Disease During Pregnancy and the Postpartum. Thyroid 27: 315-389.

9. Rai R, Backos M, Rushworth F, Regan L (2000) Polycystic ovaries and recurrent miscarriage: a reappraisal. Hum Reprod 15: 612-615.

10. Kazerooni T, Gahffarpasand F, Asadi N, Dehkoda Z, Dehghankhalili M, et al. (2013) Correlation between thrombophilia and recurrent pregnancy loss in patients with polycystic ovary syndrome: A comparative study. J Chin Med Assoc 76: 282-288.

11. de Jong PG, Kaandorp S, Di Nisio M, Goddijn M, Middeldorp S (2014) Aspirin and/or heparin for women with unexplained recurrent miscarriage with or without inherited thrombophilia. Cochrane Database Syst Rev 4: CD004734.

12. Little AB (1988) There's many a slip 'twixt implantation and the crib. N Engl J Med 319: 241-242.

13. Laird SM, Tukerman EM, Cork BA, Linjawi S, Blakemore AIF, et al. (2003) A review of immune cells and molecules in women with recurrent miscarriage. Hum Reprod Update 9: 163-174.

14. Clifford K, Flanagan AM, Regan L (1999) Endometrial CD56+ natural killer cells in women with recurrent miscarriage: a histomorphometric study. Hum Reprod 14: 2727-2730.

15. Quenby S, Bates M, Doig T, Brewster J, Lewis-Jones DI, et al. (1999) Pre-implantation endometrial leukocytes in women with recurrent miscarriage. Hum Reprod 14: 2386-2391.
16. Lachapelle MH, Miron P, Hemmings R, Roy DC (1996) Endometrial T, $\mathrm{B}$, and NK cells in patients with recurrent spontaneous abortion. Altered profile and pregnancy outcome. J Immunol 156: 4027-4034.

17. Sullivan AE, Silver RM, LaCoursiere DY, Porter TF, Branch DW (2004) Recurrent fetal aneuploidy and recurrent miscarriage. Obstet Gynecol 104: 784-788.

18. Stirrat GM (1990) Recurrent miscarriage I: definition and epidemiology. Lancet 336: 673-675.

19. Stephenson MD, Awartani KA, Robinson WP (2002) Cytogenetic analysis of miscarriages from couples with recurrent miscarriage: a casecontrol study. Hum Reprod 17: 446-451.

20. Kalousek DK, Pantzar T, Tsai M, Paradice B (1993) Early Spontaneous Abortion: Morphologic and Karyotypic Findings in 3,912 Cases. Birth Defects Orig Artic Ser 29: 53-61.

21. Fritz B, Hallermann C, Olert J, Fuchs B, Bruns M, et al. (2001) Cytogenetic Analyses of Culture Failures by Comparative Genomic Hybridisation (CGH)-Re-evaluation of Chromosome Aberration Rates in Early Spontaneous Abortions. Eur J Hum Genet 9: 539-547.

22. Rajcan-Separovic E (2020) Next Generation Sequencing in Recurren Pregnancy Loss-Approaches and Outcomes. Eur J med Gen 63: 103644.

23. Quintero-Ronderos P, Mercier E, Fukuda M, González R, Suárez CF, et al. (2017) Novel genes and mutations in patients affected by recurrent pregnancy loss. PLoS One 12: 0186149.

24. Preston FE, Rosendaal FR, Walker ID, Briët E, Berntorp E, et al. (1996) Increased fetal loss in women with heritable thrombophilia. Lancet 348 913-916

25. Sanson BJ, Friederich PW, Simioni P, Zanardi S, Hilsman MV, et al (1996) The risk of abortion and stillbirth in antithrombin-, protein C-, and protein S-deficient women. Thromb Haemost 75: 387-388.

26. Rai R., Regan L (2006) Recurrent Miscarriage. Lancet 368: 601-611.

27. Rey E, Kahn SR, David M, Shrier I (2003) Thrombophilic disorders and fetal loss: a meta-analysis. Lancet 361: 901-908.

28. Rai R, Backos M, Elgaddal S, Shlebak A, Regan L (2002) Factor V Leiden and Recurrent Miscarriage-Prospective Outcome of Untreated Pregnancies. Hum Reprod 17: 402-405.

29. Dizon-Townson D, Miller C, Sibai B, Spong CY, Thom E, et al. (2005) The relationship of the factor $\mathrm{V}$ Leiden mutation and pregnancy outcomes for mother and fetus. Obstet Gynecol 106: 517-524.

30. Silver RM, Zhao Y, Spong CY, Sibai B, Wendel G, et al. (2010) Eunice Kennedy Shriver National Institute of Child Health and Human Development Maternal-Fetal Medicine Units (NICHD MFMU) Network. Prothrombin gene G20210A mutation and obstetric complications. Obstet Gynecol 115: 14-20.

31. Said JM, Higgins JR, Moses EK, Walker SP, Borg AJ, et al. (2010) Inherited thrombophilia polymorphisms and pregnancy outcomes in nulliparous women. Obstet Gynecol 115: 5-13. 


\section{di \\ нвам}

Advances In Industrial Biotechnology | ISSN: 2639-5665

Advances In Microbiology Research | ISSN: 2689-694X

Archives Of Surgery And Surgical Education | ISSN: 2689-3126

Archives Of Urology

Archives Of Zoological Studies | ISSN: 2640-7779

Current Trends Medical And Biological Engineering

International Journal Of Case Reports And Therapeutic Studies | ISSN: 2689-310X

Journal Of Addiction \& Addictive Disorders | ISSN: 2578-7276

Journal Of Agronomy \& Agricultural Science | ISSN: 2689-8292

Journal Of AIDS Clinical Research \& STDs | ISSN: 2572-7370

Journal Of Alcoholism Drug Abuse \& Substance Dependence | ISSN: 2572-9594

Journal Of Allergy Disorders \& Therapy | ISSN: 2470-749X

Journal Of Alternative Complementary \& Integrative Medicine | ISSN: 2470-7562

Journal Of Alzheimers \& Neurodegenerative Diseases | ISSN: 2572-9608

Journal Of Anesthesia \& Clinical Care | ISSN: 2378-8879

Journal Of Angiology \& Vascular Surgery | ISSN: 2572-7397

Journal Of Animal Research \& Veterinary Science | ISSN: 2639-3751

Journal Of Aquaculture \& Fisheries | ISSN: 2576-5523

Journal Of Atmospheric \& Earth Sciences | ISSN: 2689-8780

Journal Of Biotech Research \& Biochemistry

Journal Of Brain \& Neuroscience Research

Journal Of Cancer Biology \& Treatment | ISSN: 2470-7546

Journal Of Cardiology Study \& Research | ISSN: 2640-768X

Journal Of Cell Biology \& Cell Metabolism | ISSN: 2381-1943

Journal Of Clinical Dermatology \& Therapy | ISSN: 2378-8771

Journal Of Clinical Immunology \& Immunotherapy | ISSN: 2378-8844

Journal Of Clinical Studies \& Medical Case Reports | ISSN: 2378-8801

Journal Of Community Medicine \& Public Health Care | ISSN: 2381-1978

Journal Of Cytology \& Tissue Biology | ISSN: 2378-9107

Journal Of Dairy Research \& Technology | ISSN: 2688-9315

Journal Of Dentistry Oral Health \& Cosmesis | ISSN: 2473-6783

Journal Of Diabetes \& Metabolic Disorders | ISSN: 2381-201X

Journal Of Emergency Medicine Trauma \& Surgical Care | ISSN: 2378-8798

Journal Of Environmental Science Current Research | ISSN: 2643-5020

Journal Of Food Science \& Nutrition | ISSN: 2470-1076

Journal Of Forensic Legal \& Investigative Sciences | ISSN: 2473-733X

Journal Of Gastroenterology \& Hepatology Research | ISSN: 2574-2566
Journal Of Genetics \& Genomic Sciences | ISSN: 2574-2485

Journal Of Gerontology \& Geriatric Medicine | ISSN: 2381-8662

Journal Of Hematology Blood Transfusion \& Disorders | ISSN: 2572-2999

Journal Of Hospice \& Palliative Medical Care

Journal Of Human Endocrinology | ISSN: 2572-9640

Journal Of Infectious \& Non Infectious Diseases | ISSN: 2381-8654

Journal Of Internal Medicine \& Primary Healthcare | ISSN: 2574-2493

Journal Of Light \& Laser Current Trends

Journal Of Medicine Study \& Research | ISSN: 2639-5657

Journal Of Modern Chemical Sciences

Journal Of Nanotechnology Nanomedicine \& Nanobiotechnology | ISSN: 2381-2044 Journal Of Neonatology \& Clinical Pediatrics | ISSN: 2378-878X

Journal Of Nephrology \& Renal Therapy | ISSN: 2473-7313

Journal Of Non Invasive Vascular Investigation | ISSN: 2572-7400

Journal Of Nuclear Medicine Radiology \& Radiation Therapy | ISSN: 2572-7419

Journal Of Obesity \& Weight Loss | ISSN: 2473-7372

Journal Of Ophthalmology \& Clinical Research | ISSN: 2378-8887

Journal Of Orthopedic Research \& Physiotherapy | ISSN: 2381-2052

Journal Of Otolaryngology Head \& Neck Surgery | ISSN: 2573-010X

Journal Of Pathology Clinical \& Medical Research

Journal Of Pharmacology Pharmaceutics \& Pharmacovigilance | ISSN: 2639-5649

Journal Of Physical Medicine Rehabilitation \& Disabilities | ISSN: 2381-8670

Journal Of Plant Science Current Research | ISSN: 2639-3743

Journal Of Practical \& Professional Nursing | ISSN: 2639-5681

Journal Of Protein Research \& Bioinformatics

Journal Of Psychiatry Depression \& Anxiety | ISSN: 2573-0150

Journal Of Pulmonary Medicine \& Respiratory Research | ISSN: 2573-0177

Journal Of Reproductive Medicine Gynaecology \& Obstetrics | ISSN: 2574-2574

Journal Of Stem Cells Research Development \& Therapy | ISSN: 2381-2060

Journal Of Surgery Current Trends \& Innovations | ISSN: 2578-7284

Journal Of Toxicology Current Research | ISSN: 2639-3735

Journal Of Translational Science And Research

Journal Of Vaccines Research \& Vaccination | ISSN: 2573-0193

Journal Of Virology \& Antivirals

Sports Medicine And Injury Care Journal | ISSN: 2689-8829

Trends In Anatomy \& Physiology | ISSN: 2640-7752

Submit Your Manuscript: https://www.heraldopenaccess.us/submit-manuscript 